\title{
Non-verbal Communication Approach to Inculcating Moral Values in Tertiary Institutions
}

\author{
Alaiyemola Anne Omotayo \\ University Wide Courses Directorate, Landmark University, Omu-Aran, Nigeria \\ Email address: \\ alaiyemola.tayo@1mu.edu.ng

\section{To cite this article:} \\ Alaiyemola Anne Omotayo. Non-verbal Communication Approach to Inculcating Moral Values in Tertiary Institutions. English Language, \\ Literature \& Culture. Vol. 2, No. 2, 2017, pp. 12-16. doi: 10.11648/j.ellc.20170202.11
}

Received: March 13, 2017; Accepted: March 24, 2017; Published: April 7, 2017

\begin{abstract}
Having observed that lack of moral values is one of the major causes leading to break down of laws and order and in spite of preaching, sermonizing and talking that seem to yield no positive change; there ought to be something non-verbally that can be done without even uttering a word. Every society is faced with one problem or the other. However, the so-called societal problems, upon careful and final analysis, dissolve in moral problems. The social, economic, religious, political, cultural, technological and educational problems facing nations all over the world are essentially moral in nature and character. The mere rhetoric of been found worthy in character and learning read at universities convocation ceremonies is a far cry from what is actually obtainable. Ultimately suggestion of a network of paralinguistic phenomena that have potentials of enhancing and advancing the moral values of university students are highlighted. It is recommended that para-linguistic theory and practice of non-verbal communication be vigorously applied by lecturers who would be adequately balanced so that students would achieve a combined academic and moral educational worth that will benefit humanity.
\end{abstract}

Keywords: Sermonizing, Non-verbal Communication, Moral Values, Character, Educational Worth

\section{Introduction}

The impacts of science and technology, the negative roles of civilization and modernization, the degeneration of the society from community to atomism and the wide-spread of materialism and materialistic tendencies, and so on, make teaching of moral instructions very pertinent and urgent especially to our teeming universities students. There is a lot of religious activities going on everywhere you turn to. In fact, Nigeria is said to be the second largest religious nation after South Korea. The contribution of religion has made the sermons in the churches and mosques watery and empty. There can be no true religion without morality. Religion has become an instrument of manipulation, exploitation, deceit, and large scale blindfolding of ordinary people. Knowing how to preach moral instruction is never the same as moralizing the students. Example is always better than precepts. What this point boils down to is that, it is possible for lecturers to be able to teach moral concepts and theories very well but if he does not live what he teaches, the desired outcome may not be achieved.

\section{Literature Review}

Many verbal expressions point to the importance of nonverbal communication. Wright believes that "we communicate more through actions than words" [1]. This agrees with the African adage that says "actions speak louder than words" or "face to face is better than hundred letters". 'Universally, non-verbal communication is essential in guiding our decisions. Some may call it "gut feeling", some may call it "impression". Whatever the term, it suggests that non-verbal messages influence the flow of the interaction before the verbal messages even have a chance to arrive' [2]. In spite of all these familiar clichés, non-verbal communication remains an underutilized area of study. Campbell and Hepleck are of the opinion that "a good deal of non-verbal communication goes on around us and it is so important because we make decisions based on it" [3]. What this implies is that decisions taken most times in life are not based on what we hear in sermons or teachings but on what is seen being practiced and actualized by those who say it.

Communication in general is a process of sending and receiving messages that enables humans to share knowledge, 
attitudes and skills. Although we usually identify communication with speech, it comprised of two dimensionsverbal and nonverbal. Non-verbal communication has been defined as communication without words. It includes apparent behaviours such as facial expression, eyes, touching and tone of voice as well as less obvious messages such as dress, posture and spatial distances between two or more people.

Everything communicates including material objects, physical space and time systems. Although verbal communication, output and signals can be manipulated, that is, turned off, non-verbal communication cannot. Even silence speaks. Non-verbal communication is particularly important with respect to teaching/lecturing. 'Studies suggest that as much as $75 \%$ of a teacher/lecturer's classroom management direction (intentional or otherwise) is nonverbal. Many of the cues students use to make judgments about a teacher/lecturer's competence or character are obtained by observing their non-verbal behaviour'. [4]

The above explanation is to show that paralinguistic features which are the non-verbal communication that take place all around us cannot be over-emphasised. Paralinguistic features differ from culture to culture. Grimshaw stresses the fact that "certain social relationships occur but are manifested differently in all societies" [5]. This is corroborated in Bolton assertion that 'Humans have developed different methods for establishing relationships with others, including the development of language and non-verbal methods such as facial expressions, body position or posture and gestures. Each of these methods can convey part of the intended information and feelings of the speaker or interlocutor to another person or listener'. [6] That is because these differences depend on the environment or setting for their meaning based on presumption, world knowledge. For instance in Nigeria, the use of the left hand is a sign of disrespect and a way of saying 'I am not interested in greeting you'. According to Adeoye "a slow handclap is an expression of disgust in Britain, to the Greek, shaking of the head from side to side in a rocking motion means "yes or I agree" [7]. Despite all these differences from one culture to the other, 'there are still many universal paralinguistic features that convey the same meaning'. [8] There are different kinds of paralinguistic features which include:

\section{Methodology}

This being a qualitative research, based on the foregoing, some 100 Landmark University students were observed. Their selection is hinged on random sampling procedure. In formal (and informal) encounters with the students, the nonverbal approach to education and communication is experimented, demonstrated and taught. Each subject manifests some or all of the following behaviours in the classroom context:

a. Playing games and watching films

b. Failing to comply with instructions

c. Day dreaming on the course of lectures d. Showing signs of speech problem

e. Appearing disinterested, dull and lazy

f. Requesting for repetition of statements

g. Staring at the lecturer's face

h. Sleeping on the course of lectures

All these behaviours displayed in the course of teaching have paralinguistic imports and interpretations which may border on lack of morals and ethical values. From the primordial times, teaching/lecturing had been found as a veritable means of educational empowerment. Teachers/Lecturers have therefore used many methods towards attaining the goal of education which more or less border on national rejuvenation and global transformation. In other words, teaching methods have emerged to achieve functional learning. 'The most common of these methods are: the lecture method, the discussion method, the demonstration method, the laboratory use method and questioning techniques'. [9] 'Others include field trip method, project method and question mapping techniques used especially in tertiary institutions'. [10]

\section{Paralinguistic Features}

1. Facial Expression: The eyes have been described as "gateway to the soul". They convey more messages and feelings than any other part of the body. Generally speaking, lack of eye contact indicates lack of interest, honesty, or the person is discussing something intimate or difficult. Goffman states that "every person lives in a world of social encounter involving him either in face to face of mediated contact with other participants". He therefore defines face "as the positive social value a person effectively claims for himself by the line others assume he has taken during a particular contact". [11] This analysis of the paralinguistic feature of the facial expression in lecturing is very important because man, wherever he finds himself and especially in the midst of others tends to project a good image of or about himself. Facial expression therefore works better as a way of providing feedback from the students. Looking into their faces and reading meaning necessary to bring out the best from them.

2. Voice qualities: These include pitch range, degree of voice hoarseness, sharp or smooth transition in pitch, articulation, control, resonance and tempo. The implication of these is that lecturers are supposed to project and articulate ideas appropriately in class. Without appropriate voice qualities and vocalization strategies, many students that listen will not hear what is being said [12].

3. Kinesics: This is the study of facial expression, eye movements which convey meaning. Kinesics consists of illustrators, regulators, emblems, affect displays, adapters and posture. All these border on communicating with parts of body to evoke meaning and communicate sense. 'Body movement is one of the first modes of communication between babies and their 
parents. Scholars consider body gestures to be a more fundamental and universal mode of communication than vocal languages' [13] This also holds a lot of potentials for the students. Lectures that are not complemented with gestures and gesticulations, eyes movement and facial expression are often boring to the students. Looking straight into students' eyes have a way of passing a message to them. Using eye contact with students is instrumental for a teacher/lecturer to establish trust with them. Holding a firm gaze allows the lecturer to be more confident and in turn enables students to become part of what the teacher/lecturer is saying.

4. Posture: This is the way one sits, stands or walks. Identifying various postures and imparting their meanings in students ultimately assist their comprehension. Communication is dynamic: the manner of sitting will project one's moral background. Walking sluggishly, briskly, smartly, haughtily, etc. have a way of projecting one's attitude generally to activities and life.

5. Haptics: This is the touching behaviour or the use of touch to communicate. Shaking students, holding their arms, patting their backs have a way of assuring them. Some students could be stimulated by haptics to be more hardworking. This touching behaviour will be limited to certain areas of the functional - professional type, not the love - intimacy, sexual - arousal etc. types [14]. To touch or hold students indiscriminately, especially the opposite sex, is tantamount to moral debauchery on the part of lecturers, not 'haptics' any longer!

6. Proxemics: This is the use of distance or space to communicate. According to Hall, distance can be categorized into four groups: intimate (up to $45 \mathrm{~cm}$ or 18 inches), personal (up to $1,2 \mathrm{~m}$ or 4 feet), social (up to $3 \mathrm{~m}$ or $10 \mathrm{feet}$ ), and public (larger than $3 \mathrm{~m}$ ). [15] It is generally noted that closeness means intimacy and friendliness while detachment or distance suggests hostility or lack of concern. The students should be made to sit in rows close enough to the lecturers so as to bridge the public space. 'Personal and social space should also be reduced in such a way that such students would want to communicate freely with the lecturers'. [12]

7. Chronemics: This is the use of time to communicate. One good way of instilling the message of punctuality and time consciousness in the students, being morally upright or otherwise, is one's attitudes to time. A lecturer that makes a habit of keeping students waiting for ten to fifteen minutes every time into the hour before his arrival is communicating irresponsibility, inefficiency and lack of dignity to the students which the students will definitely imbibe. "Punctuality is the soul of business". Any lecturer who cannot inculcate punctuality to students is simply telling and teaching them not to do well in the world of work.
8. 'Appearess': This is our blend of dress and appearance, which often communicate. 'Tidiness, cleanliness and neatness are communicated through how students and lecturers appear' [16]. Skimpy and see through dresses suggest lack of moral values. Crazy and unconventional hair styles, make-up and use of jewelleries serve as windows into the personalities. Lecturers are supposed to transmit positive societal values through their 'appearess' every time. They are also supposed to teach those values by the way they appear at all times. Students will even be mindful and conscious of dressing well for your lectures if they know you will not dress anyhow nor tolerate them dressing otherwise.

9. Iconics: This is the use of visual objects, designs, pictures and symbols to communicate knowledge. The use of projectors and audio - visual materials is also part of iconics. Photographs, paintings, drawings and visual designs could be used to empower the students to develop their cognition. This essentially involves using projectors in all forms to achieve education.

10. The following schema provides a summary of our paralinguistic paradigm for teaching undergraduates:

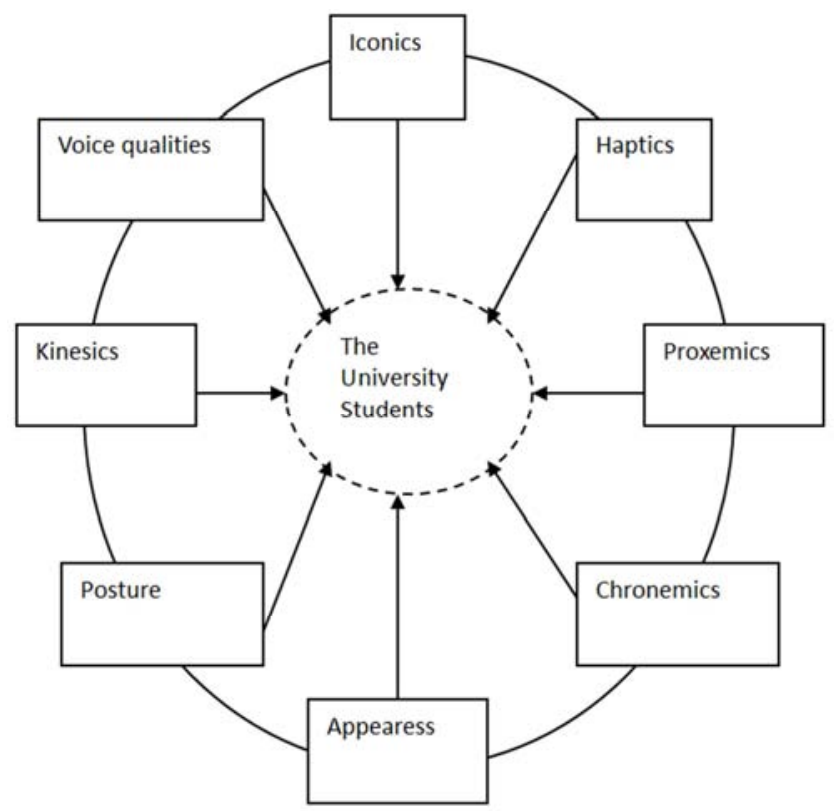

Figure 1. A paralinguistic model for the moral empowerment of University Students.

As the above model shows, access to the cognition or perception of the lack of morals is not open, yet it is not closed (represented by the broken lines). When a network of paralinguistic phenomena is deployed to communicating with, and inculcating morals, good results are achieved. A model of this nature will be a crucial, goal-oriented, targetdriven instructional approach, the dearth of which 'lamentably results in low intelligence quotient and lack of reasoning consciousness' [17]. When morals and ethical values are situated in the heart/centre of pedagogy, information and education will be in students' possession as 
they now revolve around them. The outer circle networking elements of paralanguage indicates that communication is dynamic and is always in a state of flux.

\section{Data Analysis}

At the end of the experiment, it is found out that solutions can be proffered to the lack of morals being displayed by many of the students.

\begin{tabular}{llll}
\hline \multicolumn{1}{c}{$\begin{array}{l}\text { Observed Features of } \\
\text { University Students }\end{array}$} & $\begin{array}{l}\text { Adopted Paralinguistic } \\
\text { Strategies/Elements }\end{array}$ & Frequency \\
\hline a $\begin{array}{l}\text { Playing games and watching } \\
\text { films on laptops }\end{array}$ & Proxemics and kinesics & 28 \\
\hline b $\begin{array}{l}\text { Failing to comply with } \\
\text { instructions } \\
\text { Day dreaming on the course } \\
\text { of lectures }\end{array}$ & Voice qualities & 12 \\
\hline d $\begin{array}{l}\text { Showing signs of speech } \\
\text { problem }\end{array}$ & Iconics and voice qualities & 2 \\
\hline e $\begin{array}{l}\text { Appearing disinterested, dull } \\
\text { and lazy }\end{array}$ & $\begin{array}{l}\text { Postures and appearess } \\
\text { Requesting for repetition of } \\
\text { statements }\end{array}$ & $\begin{array}{l}\text { Voice qualities/qualifiers } \\
\text { and proxemics } \\
\text { Totality of paralinguistic }\end{array}$ & 16 \\
\hline behaviour & 5 \\
\hline Staring at the lecturer's face & $\begin{array}{l}\text { Sleeping on the course of } \\
\text { lectures }\end{array}$ & $\begin{array}{l}\text { Haptics and iconics } \\
\text { Total }\end{array}$ & 20 \\
\hline
\end{tabular}

It is obvious from the foregoing that morality is a major problem among the students. Interestingly, many people/students who lack morals would not want to agree or even see it that way as they would insist that it is the teacher/lecturer who is not setting good examples or even loud enough for them to hear well. The study has further revealed that students who look dull and detached; day dreaming; watching films and playing games are often having moral problems. It is also evident that tiredness or boredom is not absolutely what makes students sleep in class, morally unbalanced students resort to sleep since there is no respect for their parents or the lecturers. Essentially, a paralinguistic approach to teaching and the total communication concept it embraces will go a long way in assisting and empowering students to learn better. The reality of the contemporary world is that just as the challenges of work and the socio-economic dynamics are making people "go mad", the cacophony of blasting music and booming sounds that consistently jar ear drums eventually are the result of lack of consideration for others.

At the end of the brief experimentation of this paralinguistic methodology, many of the students became more responsive to class tasks and livelier in teachinglearning process. The approach of not just standing in front of the class but moving around to close distance, regulating pitch and tempo, demonstrating, gesticulating, tapping their hands, patting their shoulders eventually made the classroom interesting. The success of the approach is observed in the students who show appreciation verbally and non-verbally. There is a sharp reduction in the observed features as lecture periods became interactive sessions of stimulating teaching- learning process, not mere academic ritual that one expects to end quickly. In the process of interaction, teachers/lecturers are able to inculcate moral values to students without shouting or even preaching at them.

\section{Recommendations}

Based on the preceding findings, the following recommendations are considered pertinent to empowering students:

I. The theory and practice of non-verbal communication be adopted by lecturers in their teaching with a view to stimulating students' interest as well as empowering them towards moral values.

II. The principles and precepts of moral/ethical education be incorporated into the higher pedagogical practice. Studies, and this is not an exemption, have shown that more students need these moral instructions/education than those who are traditionally reckoned as bad guys, black horse or scum of their families.

III.Lecturers be encouraged to develop more interest in the intuitively, cognitively and moral/ethical upbringing of all students so as to be able to assist them. A good training programme like the one National Universities Commission (NUC) facilitated through Philosophy and Logic some years back should be sustained for the training and re-training of lecturers for them to be adequately equipped with the theoretical and practical aspects of moral/ethical education.

\section{Conclusion}

This study has investigated the nature of special need for inculcating moral education with a focus on paralinguistic features in achieving this feat. Landmark University students are made as subjects with which the research is experimented. It is contended that the need for empowering the university students is urgent against the observation that poor academic performance is often hinged on students' inability to appreciate moral values and therefore could not absorb lectures. With this communication breakdown, dullness and boredom are often registered on the students who find themselves helpless. A paralinguistic approach, which entails total communication, to higher education pedagogy is advanced and recommended, rather than the traditional 'chalk-talk' approach or the manual communicative method.

The paralinguistic model which serves as the crux of this study is therefore suggested as an appropriate teaching model for the very well-behaved students, the averagely wellbehaved students and students who lack morals and unruly. Thus, as Sajjadi concluded in his study, "verbal and nonverbal communication could influence social skills of the people' [18] both students and lecturers alike. It is believed that this approach has the capacity of empowering, assisting, challenging and sustaining the reasoning skills and cognitive ability of the students. Such as "the powers to language", the 
"magic of language" and the "powerful tool of language" constitute the basis for human development [19] the dynamics of paralanguage have the potentials of developing, improving and enabling the morally bankrupt members of the society, especially the university students to embrace values and morally acceptable lifestyle.

\section{References}

[1] Wright, A. (1989). How to Communicate Successfully. England; Cambridge University Press.

[2] Samovar et al. (2009). Communication between cultures. Cengage Learning. International Student edition pp 196.

[3] Campbell, J. H. \& Hepleck, J. (1966). Dimensions in Communication Readings. California; Wadsworth Publication Company Int.

[4] Balzer, (1969). Nonverbal Communication for Educators In Creducation.org/resources/NonVerbal Communication/index.html

[5] Grimshaw, A. D. (1981). Language as a Social Resource: Essays, Stanford, California: Standard University Press.

[6] Bolton R, 2007. Psychology of Human Relations (people skills). Translated by Hamid RezaSohrabi and Afsane Hayat Roshanee. Tehran: Roshd.

[7] Adeoye, S. (1997). "An analysis of the Paralinguistic Elementin Selected Newspapers Obituaries". B. A. long essay. University of Ilorin.

[8] Corner, J. \& Hawthorn, W. H. (1993). Communication Studies; An introductory Reader. London; Edward Arnold.

[9] Adedimeji, M. A. (2011). "Towards a Pragma-integrative Approach to the Teaching of 'Use of English' in Nigeria: A Case for Human Development". In Opoku-Agyemang, K. (ed.) Culture, Science and Sustainable Development in Africa. Cape Coast: University of Cape Coast Press. pp.178 $-193$.

[10] Daramola, S. O. (1994). Basic Principles of Instruction. Ilorin: Lekan Printing Press.

[11] Goffman, E. (1967). Interaction Rituals. New York: Double day \& Company Int.

[12] Oyewo, Yinka (2000). "Human Communication: An Introduction". In Babajide, A. O. (Ed.) Studies in English Language Ibadan: Enicrownfit Publishers pp. 149-167.

[13] Danesi, Marcel, ed. (2004). Messages, signs, and meanings: A basic textbook in semiotics and communication, 3rd ed. Canadian Scholars' Press. p 57.

[14] O' Hair, Ban et al. (1995). Competent Communication New York: St Martins Press Inc.

[15] Hall, Edward T. (1960). "The silent language in overseas business." Harvard Business Review 38, no. 3 p 89.

[16] Adedimeji, M. A. (2006). "Nonverbal Semantics" (Supplementary Essay Two). In Odebunmi, Akin. Meaning in English: An Introduction. Ogbomoso: Critical Sphere, LAUTECH. pp. 157-172.

[17] Shonibare, O. O. (1990). "Effects of Reading Comprehension Strategies on the Comprehension, Language Skills and Attitudes of deaf Students". Unpublished Ph.D Thesis University of Ibadan.

[18] Sajjadi M, 2010. The relationship between nonverbal communication and social development among students of Shahid Bahonar University. MA thesis, Allameh Tabatabai University.

[19] Adedimeji, M. A. (2004). "Language in Guidance and Counselling: A Psychotherapy for Combating Anti-social Behaviours in Nigeria". Unpublished Module 6 Project. NUCVIHEP February. 